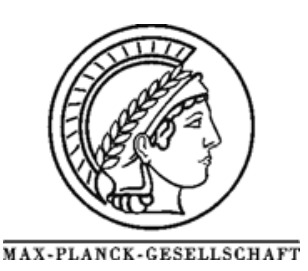

\title{
Redox Properties of Vanadium lons in SBA-15-Supported Vanadium Oxide: An FTIR Spectroscopic Study
}

\author{
T.V. Venkov, C. Hess*, F.C. Jentoft
}

Department of Inorganic Chemistry, Fritz-Haber-Institute of the MPG, Faradayweg 4-6, 14195 Berlin, Germany

* Corresponding author: e-mail hess@fhi-berlin.mpg.de,

Received August 1, 2006. In Final Form: November 1, 2006

\begin{abstract}
The state of vanadium ions in $\mathrm{V} x \mathrm{O} y / \mathrm{SBA}-15(2.7 \mathrm{wt} \% \mathrm{~V})$ was studied with FTIR spectroscopy using CO and NO as probe molecules. Neither $\mathrm{CO}$ (at $85 \mathrm{~K}$ ) nor NO (at RT) adsorb on the oxidized sample because of the coordinative saturation of $\mathrm{V}^{5^{+}}$ions and the covalent character of the $\mathrm{V}^{5+} \mathrm{dO}$ bond. After treatment of the sample in $50 \mathrm{kPa} \mathrm{H}_{2}$ at $673 \mathrm{~K}$, the V5+ ions are reduced to two different types of $\mathrm{V}^{3+}$ sites, as manifested by carbonyl bands at 2189 and $2177 \mathrm{~cm}^{-1}$. In the presence of $\mathrm{O}_{2}$ at $85 \mathrm{~K}$, thus formed $\mathrm{V}^{3+}$ ions are partly oxidized to $\mathrm{V}^{4+}$ sites showing carbonylic bands at 2202 and $2190 \mathrm{~cm}^{-1}$. When the reduced sample is exposed to $\mathrm{O}_{2}$ at room temperature, the $\mathrm{V}^{3+}$ ions are fully oxidized to $\mathrm{V}^{5^{+} \text {. The adsorp- }}$ tion of $\mathrm{NO}$ on the reduced $\mathrm{V} x \mathrm{O} y / \mathrm{SBA}-15$ shows that the $\mathrm{V}^{3+}$ and $\mathrm{V}^{4+}$ ions possess two effective coordinative vacancies and as a result can adsorb two NO molecules forming the respective $\mathrm{V}^{3+}(\mathrm{NO})_{2}$ and $\mathrm{V}^{4+}(\mathrm{NO})_{2}$ dinitrosyls. The introduction of $\mathrm{O}_{2}$ to the $\mathrm{V} x \mathrm{O} / \mathrm{SBA}-15-\mathrm{NO}$ system leads to reoxidation of the $\mathrm{V}^{3+}$ and $\mathrm{V}^{4^{+}}$ions to $\mathrm{V}^{5^{+}}$and formation of bridged $\left(1639 \mathrm{~cm}^{-1}\right)$ and bidentate $\left(1573 \mathrm{~cm}^{-1}\right)$ surface nitrates. After coadsorption of $\mathrm{CO}$ and NO on the reduced sample the formation of surface mixed carbonyl-nitrosyls (2108 and $1723 \mathrm{~cm}-1)$ was observed for the first time.
\end{abstract}

\section{Introduction}

Vanadium-containing catalysts are used in a large number of heterogeneous catalytic reactions such as oxidative dehydrogenation of alkanes, ${ }^{1-4}$ oxidation of aromatic hydrocarbons, ${ }^{5,6}$ and selective catalytic reduction of nitrogen oxides. ${ }^{7,8}$ According to the literature, the catalytic behavior of vanadium catalysts strongly depends on (i) the content and respective distribution of vanadium species, ${ }^{9-11}$ (ii) the oxidation state of vanadium, ${ }^{12}$ and (iii) the support material. ${ }^{13-16}$ Several studies have reported a correlation between the oxidation state of vanadium and its reactivity behavior. $^{12,17}$ From this point of view, it is important to have detailed knowledge of the redox properties of the respective catalysts. One of the most established techniques for determining the nature of cationic sites that are accessible for adsorption is the FTIR spectroscopy of adsorbed CO. ${ }^{18,19}$ On the basis of previous studies ${ }^{17,18,20-28}$ on supported vanadia, the main criteria for distinguishing different vanadium oxidation states are (i) the frequency of the absorption bands and (ii) the stability of the respective adsorbate complexes. It has been shown that $\mathrm{V}^{5^{+}}$ions do not form carbonyl complexes due to their coordinative saturation and the covalent character of the VdObond. ${ }^{17,18,20-28}$
$\mathrm{V}^{4+}$ ions form only ó-bonds with CO molecules. As a result, the corresponding carbonyls absorb in the spectral range of $2212-2180 \mathrm{~cm}^{-1}$ and are characterized by very low stability. ${ }^{17,18,24-26}$ A decrease in the positive charge of the vanadium ions, which is equivalent to an increase in population of the d-orbitals, leads to higher contributions of $\delta$ bonding between the vanadium ions and the adsorbed CO molecules.18 Therefore, $\mathrm{V}^{3^{+}}$ions can form weak $\partial$-bonds with $\mathrm{CO}$ molecules, and the respective carbonyls appear at lower frequencies (2197-2174 $\left.\mathrm{cm}^{-1}\right){ }^{17,18,20,21}$ In contrast, $\mathrm{V}^{2+}$ ions have a smaller charge and a higher d-electron density, and hence they form strong $ð$-bonds with CO molecules. The respective $\mathrm{V}^{2+-} \mathrm{CO}$ complexes absorb at about $2150 \mathrm{~cm}^{-1}$ and are characterized by very high stability.18 Summarizing, these results show that CO is a good probe molecule for determination of the oxidation state, but not the coordination state of surface vanadium ions. Previous studies on NO adsorption on supported vanadia have shown that both $\mathrm{V}^{4^{+}}$and $\mathrm{V}^{3+}$ ions can form dinitrosyls, ${ }^{17,29-}$ 32 and it was concluded that NO is a better probe molecule for determining the coordination state of vanadium sites. ${ }^{29}$

For a detailed understanding of catalyst properties, the use of materials with well-defined structure is necessary. Proceeding in this direction, we have studied a model 
catalyst consisting of highly dispersed vanadia supported on the inner surface of the mesoporous matrix of silica SBA-15. ${ }^{33,34}$ SBA-15 is a promising new support material as (i) it possesses a well-defined structure based on the presence of uniform hexagonally arrayed channels and a narrow pore size distribution, ${ }^{35}$ (ii) its large internal surface area $\left(>800 \mathrm{~m}^{2} / \mathrm{g}\right)$ allows for the dispersion of a high number of catalytically active sites, ${ }^{33}$ and (iii) its thick framework walls (3.1-6.4 $\mathrm{nm}$ ) provide considerable hydrothermal stability, which exceeds those of the thinner-walled MCM41 materials. Only recently, we have demonstrated the excellent performance of this catalyst system in methanol oxidation to formaldehyde and in propane oxidation to acrylic acid. ${ }^{36,37}$ Although of great potential for catalytic applications, there have been only few reports on the preparation and reactivity behavior of SBA-15- supported vanadia catalysts. ${ }^{38-41}$

The goal of this work was to investigate the state and redox properties of highly dispersed vanadia supported on mesoporous SBA-15.Weused FTIR spectroscopy and CO as a probe molecule to determine the oxidation state of the vanadium sites after different pretreatments of the sample. The coordination state of these sites was studied by adsorption of NO. To obtain more detailed information about the properties of vanadium, we investigated also the coadsorption of (i) $\mathrm{NO}+\mathrm{O}_{2}$ and (ii) $\mathrm{CO}+\mathrm{NO}$.

\section{Experimental Section}

\subsection{Reagents and Materials.}

Carbon monoxide and nitrogen monoxide were of 99.997\% and $99.5 \%$ purity, respectively. Silica SBA-15 was synthesized according to published procedures. ${ }^{35}$ Details of the catalyst preparation are described elsewhere. ${ }^{33}$ Functionalization of SBA-15 was achieved by stirring $2.5 \mathrm{~g}$ of SBA-15 in $100 \mathrm{~mL}$ of toluene at $338 \mathrm{~K}^{42}$ To this suspension was added $6.5 \mathrm{~g}$ of 3-aminopropyltrimethoxysilane (APTMS) with stirring. After stirring for $12 \mathrm{~h}$, the contents were filtered, washed with toluene, and stirred in $150 \mathrm{~mL}$ of $0.3 \mathrm{M} \mathrm{HCl}$ for $12 \mathrm{~h}$. The contents were filtered again, washed with water, and dried in air overnight. SBA-15supported vanadia was synthesized using functionalized SBA-15 and butylammonium decavanadate as starting material, which was synthesized according to a previous report. ${ }^{43}$ For a 2.7 wt\%V/SBA-15 catalyst, $73 \mathrm{mg}$ of butylammonium decavanadate was added to a suspension of 1 g of functionalized SBA-15 in $40 \mathrm{~mL}$ of water. The contents were stirred for $12 \mathrm{~h}$, filtered, washed with water, and dried in air. The resulting orange powder was calcined at $550{ }^{\circ} \mathrm{C}$ for $12 \mathrm{~h}$.

\subsection{Instrumental Methods.}

\subsubsection{Physical Characterization.}

The vanadium content of theVxOy/SBA-15 samples was determined by atomic absorption spectroscopy (AAS). The surface areas of the prepared samples were 826 and $445 \mathrm{~m}^{2} / \mathrm{g}$ for SBA-15 and $\mathrm{V} x \mathrm{O} y / \mathrm{SBA}-15$, respectively. They were measured by nitrogen adsorption/ desorption isotherms and standard multipointBETanalysis methods. For details see refs 33 and 36.

\subsubsection{FTIR Spectroscopy.}

The FTIR measurements were carried out using a Perkin-Elmer S 2000 spectrometer with a resolution of 4 $\mathrm{cm}^{-1}$ and an accumulation of 32 scans. Self-supporting wafers were obtained by pressing the powdery sample under a pressure of $10^{4} \mathrm{kPa}$. The sample was treated directly in the IR cell connected to a vacuum apparatus with a residual pressure of about $10^{-7} \mathrm{kPa}$. Prior to the adsorption measurements, the sample was evacuated at $673 \mathrm{~K}$ for $1 \mathrm{~h}$. For reduction, the samples were heated in $50 \mathrm{kPa} \mathrm{H}_{2}$ at 573 and $673 \mathrm{~K}$, respectively, for $1 \mathrm{~h}$ and then evacuated at the same temperature. For low-temperature CO adsorption, the sample was cooled to $85 \mathrm{~K}$ with liquid nitrogen. The evacuated cell with $\mathrm{CaF}_{2}$ windows was used to generate a background spectrum. Presented are difference spectra obtained through subtraction of the spectrum of the treated sample in vacuum from the spectrum in presence of the probe.

\subsubsection{X-ray Photoelectron Spectroscopy.}

The measurements were carried out using a modified LHS/SPECS EA200 MCD system equipped with a Mg Ka source (1253.6 eV, $168 \mathrm{~W})$. The binding energy scale of the system was calibrated using $\mathrm{Au} 4 \mathrm{f}_{7 / 2}$ ) $84.0 \mathrm{eV}$ and $\mathrm{Cu} 2 \mathrm{p}_{3 / 2}$ ) $932.67 \mathrm{eV}$ from foil samples. The powder samples were placed as-is in a stainless steel sample holder with a $0.6 \mathrm{~mm}$ deep rectangular well covering an area of (12x8) $\mathrm{mm}^{2}$. The base pressure of the ultrahigh vacuum chamber was $1 \times 10^{-11} \mathrm{kPa}$. Charging of the powder samples was accounted for by setting the peak of the Si $2 p$ signal to $103.6 \mathrm{eV}^{44}$ Further data reduction included satellite removal and subtraction of a Shirley background. Quantitative data analysis was performed on the basis of peak areas by fitting with 30/70 Gauss-Lorentz product functions. Samples were treated in $20 \mathrm{kPa} \mathrm{H}_{2}$ for $60 \mathrm{~min}$ at temperatures within 298-688 $\mathrm{K}$ and subsequently transferred to the analysis chamber without exposure to air (quasi in situ). 


\section{Results}

\subsection{FTIR SpectroscopysSpectrum of Activated} Sample.

In the region of $v(\mathrm{O}-\mathrm{H})$ stretching modes, the IR spectrum of activated SBA-15-supported vanadium oxide exhibits an intense band consisting of two components with maxima at 3747 and $3743 \mathrm{~cm}^{-1}$ due to $v(\mathrm{O}-\mathrm{H})$ vibrations of two types of silanol groups (spectra not shown). ${ }^{45}$ Analysis of the whole range reveals that two more bands with low intensity are present at higher frequencies, namely at 4577 and $4508 \mathrm{~cm}^{-1}$. According to literature data obtained for conventional $\mathrm{SiO}_{2}{ }^{45,46}$ they can be assigned to a combination mode of the respective stretching $\left(v_{\mathrm{OH}}=3750-3745 \mathrm{~cm}\right.$ 1) and deformation modes $\left.\left(\partial_{\mathrm{OH}}\right) 870 \mathrm{~cm}^{-1}\right)$ of silanol groups; however, the deviation from the calculated combination frequency is considerable. At lower frequencies, bands at 1975, 1871, and $1650 \mathrm{~cm}^{-1}$ were registered. These bands are attributable to overtones and combination modes of SBA-framework skeletal vibrations. ${ }^{45}$

\subsection{Low-Temperature CO Adsorption on Acti- vated $V_{x} O_{y} / S B A-15$.}

Low-temperature $\mathrm{CO}$ adsorption on an activated sample results in the appearance of three bands with maxima at 2157, 2139, and $2110 \mathrm{~cm}^{-1}$ (Figure 1, spectrum a). Simultaneously with the formation of these bands, the band of the silanol groups at $3742 \mathrm{~cm}^{-1}$ decreases in intensity and a new band with a maximum at $3641 \mathrm{~cm}^{-1}$ forms in the spectrum (Figure 1, spectrum a). Detailed analysis of the spectra reveals an isosbestic point at $3693 \mathrm{~cm}^{-1}$ between the band of the silanol group and the new band, which proves the interconversion of these two $\mathrm{OH}$-species. The band at $3641 \mathrm{~cm}^{-1}$ has a complex shape and the two other components at 3670 and $3618 \mathrm{~cm}^{-1}$ are assigned to perturbed $v(\mathrm{O}-\mathrm{H})$ stretching modes of silanol groups.

With decreasing CO coverage the bands at 2157 and $2139 \mathrm{~cm}^{-1}$ decrease in intensity and, simultaneously, the bands due to $v(\mathrm{O}-\mathrm{H})$ stretching modes are restored to their original state. The bands at 3641 and $2157 \mathrm{~cm}^{-1}$ are attributed to $v(\mathrm{O}-\mathrm{H})$ and $v(\mathrm{C}-\mathrm{O})$ stretching modes of the respective $\mathrm{OH}-\mathrm{CO}$ species that are formed through interaction of CO with silanol groups of the SBA-15 support. ${ }^{18}$ The value of the $\Delta v_{\mathrm{OH}}$ shift $\left(\approx-100 \mathrm{~cm}^{-1}\right)$ is comparable with the respective shift for the silanol groups of $\mathrm{SiO}_{2}$ $\left(\Delta v_{\mathrm{OH}} \approx-90 \mathrm{~cm}^{-1}\right)$ reported in the literature. ${ }^{18}$ It follows that the acidity of the respective silanol groups is not influenced by the bulk structure but depends only on the chemical composition of the support.

The bands at 2139 and $2110 \mathrm{~cm}^{-1}$ are assigned to physically adsorbed $\mathrm{CO}$ and $\mathrm{H}$-bonded ${ }^{13} \mathrm{CO}$, respectively. ${ }^{18}$ A summary of the observed bands and their assignment is given in Table 1.
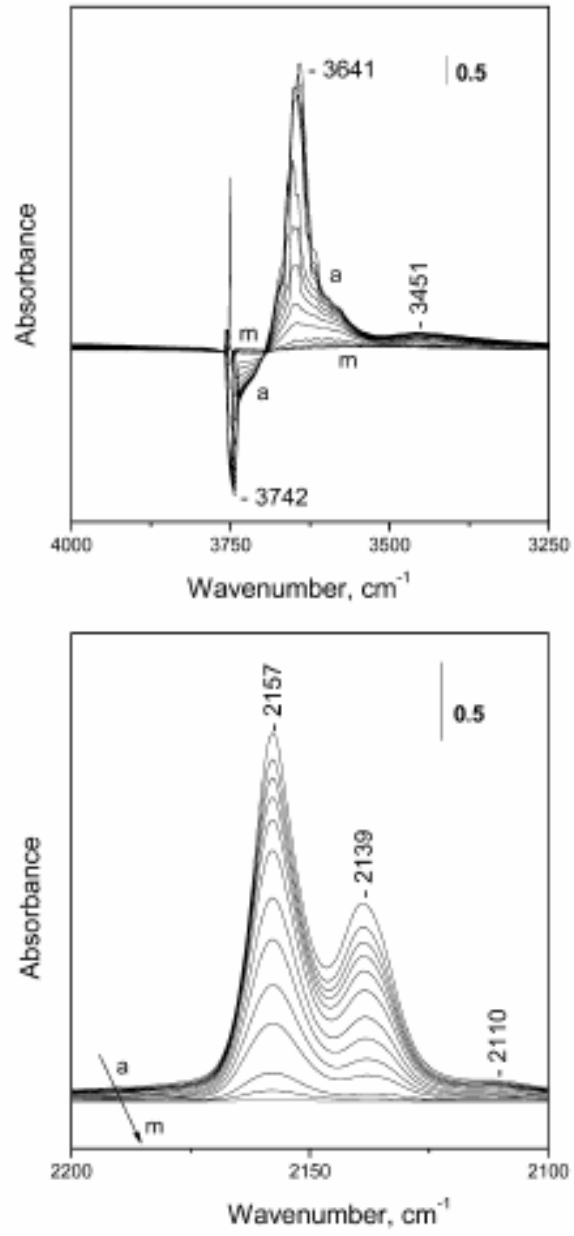

Figure 1: FTIR spectra of $\mathrm{CO}(0.12 \mathrm{kPa}$ equilibrium pressure) adsorbed at $85 \mathrm{~K}$ on $\mathrm{V} x \mathrm{O} y / \mathrm{SBA}-15$ (a); after reduction of the $\mathrm{CO}$ pressure to $0.074 \mathrm{kPa}$ (b), $0.054 \mathrm{kPa}$ (c), $0.04 \mathrm{kPa}(\mathrm{d}), 0.03 \mathrm{kPa}(\mathrm{e}), 0.02 \mathrm{kPa}(\mathrm{f}), 0.01 \mathrm{kPa}(\mathrm{g}), 0.006$ kPa (h), $0.004 \mathrm{kPa}(\mathrm{i}), 0.003 \mathrm{kPa}(\mathrm{j}), 0.0015 \mathrm{kPa}(\mathrm{k})$; and after evacuation at $85 \mathrm{~K}(\mathrm{l}, \mathrm{m})$.

\subsection{Low-Temperature CO Adsorption on Re- duced $V_{x} O_{y} / S B A-15$.}

Initially the sample was treated with $\mathrm{H}_{2}$ (50 kPa equilibrium pressure) at $573 \mathrm{~K}$ and then evacuated at the same temperature. The spectra that were registered after lowtemperature $\mathrm{CO}$ adsorption of thus-treated samples are comparable to those obtained after activation in vacuum (not shown). Hence, no significant reduction of vanadium occurs under these conditions.

The situation is different after exposure of the sample to $\mathrm{H}_{2}$ at $673 \mathrm{~K}$ and evacuation at the same temperature. Lowtemperature $\mathrm{CO}$ adsorption on the reduced sample results in the appearance of bands with maxima at 2187, 2156, 2138, and $2110 \mathrm{~cm}^{-1}$ (Figure 2, spectrum a). The bands at 2156 and $2138 \mathrm{~cm}^{-1}$ were observed after CO adsorption on the activated sample and are assigned to $v(\mathrm{C}-\mathrm{O})$ stretching modes of $\mathrm{H}$-bonded and physically adsorbed $\mathrm{CO}$, respectively. ${ }^{18}$ Upon evacuation at low temperature, all 
Table 1: Assignment of the Bands Observed after Adsorption of $\mathrm{CO}$ or $\mathrm{NO}$ and after Coadsorption of $\mathrm{NO}+\mathrm{O}_{2}$ and of $\mathrm{CO}+\mathrm{NO}$ on $\mathrm{V} x \mathrm{O} y / \mathrm{SBA}-15$

\begin{tabular}{|c|c|c|c|c|c|}
\hline bend, $\mathrm{cm}^{-1}$ & probes & species & astigrment & site & note \\
\hline $\begin{array}{l}2202 \\
2190 \\
2189 \\
2177 \\
2157 \\
2139 \\
2110\end{array}$ & $\begin{array}{l}\infty \\
\infty \\
\infty \\
\infty \\
\infty \\
\infty\end{array}$ & \multicolumn{4}{|c|}{ 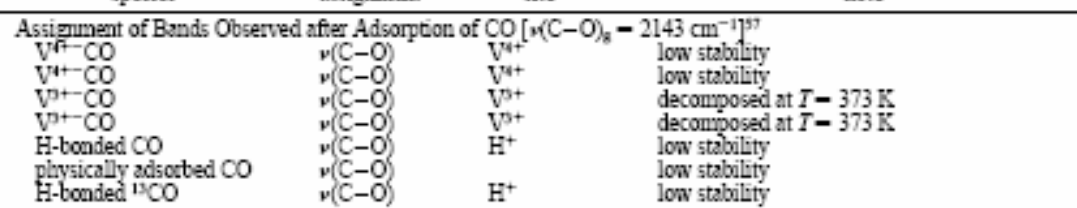 } \\
\hline $\begin{array}{l}1909 \\
1830 \\
1763 \\
1686 \\
1620\end{array}$ & $\begin{array}{l}\text { NO } \\
\text { NO } \\
\text { NO } \\
\text { NO } \\
\text { NO }\end{array}$ & \multicolumn{4}{|c|}{ 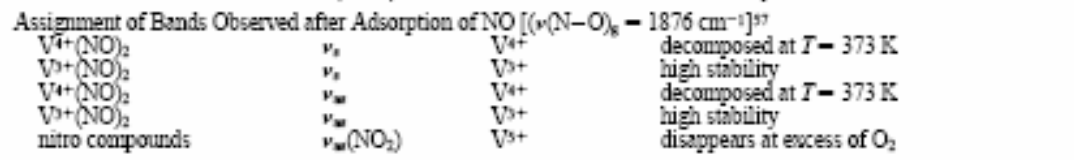 } \\
\hline $\begin{array}{l}1639 \\
1573\end{array}$ & $\begin{array}{l}\mathrm{NO}+\mathrm{O}_{2} \\
\mathrm{NO}+\mathrm{O}_{2}\end{array}$ & $\begin{array}{l}\text { Ascigument of Bum } \\
\text { bridging nitrates } \\
\text { bidentate nitrates }\end{array}$ & $\begin{array}{l}\text { Observed after } \\
v_{3} \\
v_{3}\end{array}$ & $\underset{\mathrm{V}^{5+}}{\text { tsogption of }}$ & $\begin{array}{l}\mathrm{dO}_{2} \\
\text { decourposed at } T=573 \mathrm{~K} \\
\text { decourposed at } T=573 \mathrm{~K}\end{array}$ \\
\hline $\begin{array}{l}2108 \\
1723\end{array}$ & $\begin{array}{l}\mathrm{CO}+\mathrm{NO} \\
\mathrm{CO}+\mathrm{NO}\end{array}$ & 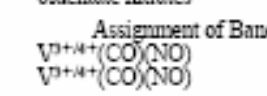 & $\begin{array}{l}\text { bserved after } \\
v(\mathrm{C}-\mathrm{O}) \\
v(\mathrm{~N}-\mathrm{O})\end{array}$ & $\begin{array}{l}\text { sorption of } \\
\mathrm{V}^{5+} \text { or } \mathrm{V}^{4} \\
\mathrm{~V}^{3+} \text { or } \mathrm{V}^{4}\end{array}$ & $\begin{array}{l}1 N O \\
\text { appenred only after interaction of } \mathrm{CO} \text { and NO } \\
\text { low intensity }\end{array}$ \\
\hline
\end{tabular}

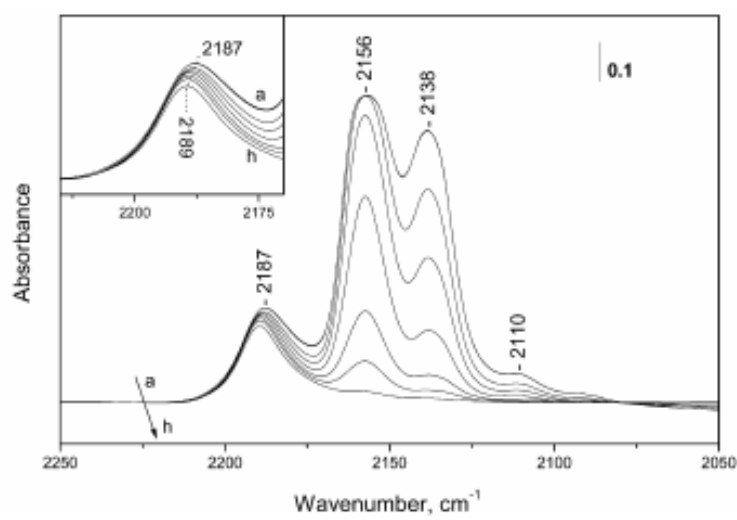

Figure 2: FTIR spectra of CO (0.13 kPa equilibrium pressure) adsorbed at $85 \mathrm{~K}$ on reduced $\mathrm{VxOy/SBA}-15$ (a); after reduction of the $\mathrm{CO}$ pressure to $0.074 \mathrm{kPa}(\mathrm{b}), 0.026 \mathrm{kPa}$ (c), $0.009 \mathrm{kPa}(\mathrm{d}), 0.004 \mathrm{kPa}(\mathrm{e}), 0.001 \mathrm{kPa}(\mathrm{f})$; and after evacuation at $85 \mathrm{~K}(\mathrm{~g}, \mathrm{~h})$.

bands in the spectrum start to decrease in intensity (Figure 2 , spectrum a). The most stable band in the spectra is the one at $2187 \mathrm{~cm}^{-1}$. This band was not detected in the spectra recorded after $\mathrm{CO}$ adsorption on vacuum-activated $\mathrm{V} x \mathrm{O} y / \mathrm{SBA}-15$ or SBA-15 treated with $\mathrm{H}_{2}$ under the same conditions and, hence, arise from vanadium carbonyls. A more detailed analysis of the behavior of these species reveals a slight blue shift of the band at $2187 \mathrm{~cm}^{-1}$ with decreasing coverage (Figure 2; see inset). This trend could be explained with the so-called static effect, which is typical for oxide-supported samples and indicates that a fraction of the vanadium sites is associated. ${ }^{18}$ However, this still leaves the question about the oxidation state of these vanadium sites open. One of the most frequently used criteria for the determination of the oxidation state of vanadium ions, besides the frequencies of the registered bands, is the stability of these carbonyls. With increasing temperature in dynamic vacuum, the intensity of this band starts to decrease (Figure 3, panel A, spectra a-h) but at room temperature the band still retains about $40 \%$ of its original intensity (Figure 3, panel A, spectrum h). After evacuation at $373 \mathrm{~K}$, the band at $2189 \mathrm{~cm}^{-1}$ disappears completely from the spectrum (Figure 3, panel A, spectrum i). The high stability of the observed complex can be explained with a synergism between ó- and $\delta$-components of the bond between vanadium and adsorbed $\mathrm{CO} .{ }^{18}$ The phenomenon of $\delta$-backdonation is typical only for vanadium ions in lower oxidation state, such as $\mathrm{V}^{3^{+}}$or $\mathrm{V}^{2^{+}}$ions. ${ }^{17,18,20,21}$ For $\mathrm{CO}$ adsorbed on $\mathrm{V} / \mathrm{SiO}_{2}$, Davydov ${ }^{17}$ detected a band at a similar position (2185 cm-1) and assigned it to V3+-CO complexes. A comparable band position around $2185 \mathrm{~cm}^{-1}$ was also observed for $\mathrm{CO}$ adsorbed on VAPO-5,20 VMgAPO-5,20 and $\mathrm{V} / \mathrm{Al}_{2} \mathrm{O}_{3}-\mathrm{TiO}_{2}{ }^{22}$ and assigned toV ${ }^{3+-} \mathrm{CO}$ species. On the basis of these literature data ${ }^{17,18,20-22}$ we assign the band at $2187 \mathrm{~cm}^{-1}$ to the $v(\mathrm{C}-\mathrm{O})$ stretching mode of $\mathrm{V}^{3+-} \mathrm{CO}$ carbonyls.

The temperature-dependent changes in the reduction behavior as well as the above assignment of the oxidation state are supported by XPS data. Figure 4 shows XP spectra of $\mathrm{VxOy/SBA}-15$ after $\mathrm{H}_{2}$ treatment at 298-688 $\mathrm{K}$ together with the results of the peakfitting procedure. For analysis, the spectra were fit with three peaks using binding energies typical for vanadium species that are interacting strongly with silica (518.7 eV), vanadium species as part of extended $\mathrm{Vx} O y$ aggregates such as in $\mathrm{V}_{2} \mathrm{O}_{5}(517.3 \mathrm{eV})$, and reduced vanadia $\left(\mathrm{V}^{3+}\right)$ species $(515.9 \mathrm{eV}) .^{47,48}$ The fwhm was held constant at $2.4 \mathrm{eV}$. The results of the peak-fitting analysis are summarized in Table 2. Figure 4 shows an increase in the amount of $\mathrm{V}^{3+}$ with increasing temperature, which amounts to $50 \%$ after $\mathrm{H}_{2}$ treatment at $688 \mathrm{~K}$. Besides the increasing degree of reduction, an increase in the intensity ratio of the peaks at 518.7 and $517.3 \mathrm{eV}$ is observed, which is a result of changes in the oxidation state distribution of vanadia upon $\mathrm{H}_{2}$ treatment and will be discussed in detail in a forthcoming publication.

Further inspection of the IR spectra shows that the band at $2187 \mathrm{~cm}^{-1}$ consists of two components with maxima around 2189 and $2177 \mathrm{~cm}^{-1}$, with the species at lower wavenumbers being slightly more stable (Figure 3, 

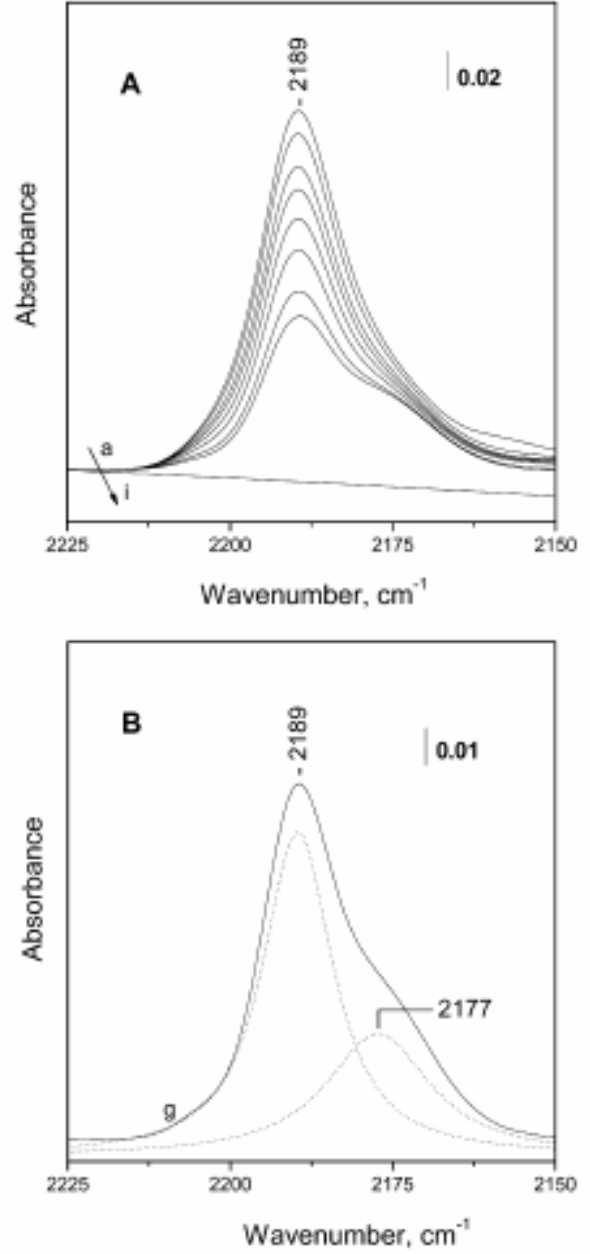

Figure 3: Stability of the carbonyls of the reduced $\mathrm{VxOy/SBA-15}$ (A) during a gradual increase of the evacuation temperature to $298 \mathrm{~K}$ (a-h), after evacuation at $373 \mathrm{~K}$ (i). (B) Spectrum h together with the results from a leastsquare fit.

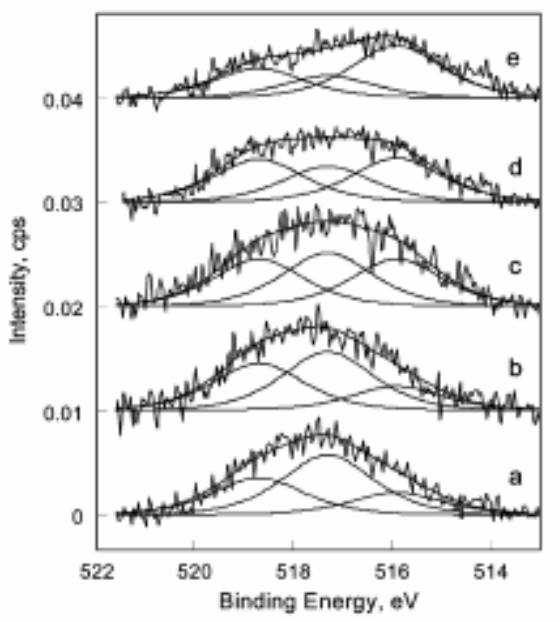

Figure 4: $\mathrm{XP} V 2_{3 / 2}$ spectra of $\mathrm{V} x \mathrm{O} y / \mathrm{SBA}-15$ together with the results from the peak-fitting procedure after treatment in $20 \mathrm{kPa} \mathrm{H}_{2}$ at $298 \mathrm{~K}$ (a), $461 \mathrm{~K}$ (b), $565 \mathrm{~K}$ (c), 660 $\mathrm{K}$ (d), $688 \mathrm{~K}$ (e). The spectra are offset for clarity.
Table 2: Results of the XPS Analysis of $\mathrm{V} x \mathrm{O} y / \mathrm{SBA}-15$ after $\mathrm{H}_{2}$ Treatment

\begin{tabular}{ccccc}
\hline temp $(\mathrm{K})$ & $\begin{array}{c}518.7 \\
(\%)\end{array}$ & $\begin{array}{c}517.3 \\
(\%)\end{array}$ & $\begin{array}{c}515.9 \\
(\%)\end{array}$ & $\begin{array}{c}A(518.7) \\
A(517.3)\end{array}$ \\
\hline 298 & 31.0 & 50.5 & 18.5 & 0.61 \\
461 & 36.3 & 45.3 & 18.4 & 0.8 \\
565 & 32.0 & 36.1 & 31.9 & 0.89 \\
660 & 34.9 & 29.3 & 35.8 & 1.19 \\
688 & 28.3 & 21.4 & 50.3 & 1.32
\end{tabular}

panels $\mathrm{A}$ and $\mathrm{B}$ ). It follows that two kinds of $\mathrm{V}^{3+}$ ions with different electrophilicity are located in the channels of the support. To obtain additional information about the nature of these $\mathrm{V}^{3+}$ sites, we investigated their reactivity with $\mathrm{O}_{2}$.

\subsection{Reoxidation of the Reduced $V_{x} \mathrm{O}_{y} / S B A-15$ Sample.}

\subsubsection{Reoxidation of the Sample with $\mathrm{O}_{2} 85 \mathrm{~K}$.}

The sample was initially reduced with $\mathrm{H}_{2}(50 \mathrm{kPa}$ equilibrium pressure) at $673 \mathrm{~K}$ and then evacuated at the same temperature. After adsorption of small amounts of $\mathrm{CO}(0.0004 \mathrm{kPa}$ equilibrium pressure) at $85 \mathrm{~K}$ only the band at $2189 \mathrm{~cm}-1$ due to $\mathrm{V}^{3+-} \mathrm{CO}$ carbonyls was detected (Figure 5, spectrum a). The presence of this band shows that after this treatment the main part of the vanadium sites is in their +3 oxidation state. The introduction of $\mathrm{O}_{2}(10$ $\mathrm{kPa}$ equilibrium pressure) into the cell leads to the following changes in the spectra: (i) the intensity of the band at $2189 \mathrm{~cm}^{-1}$ strongly decreases and (ii) several new bands with maxima at 2349, 2202, 2190, and $2157 \mathrm{~cm}^{-1}$ are observed in the spectrum.

The bands at 2349 and $2157 \mathrm{~cm}^{-1}$ are attributed to $\mathrm{CO}_{2}$ and $\mathrm{H}$-bonded $\mathrm{CO}$, respectively.18 An interesting change in the spectrum is the appearance of the two bands at 2202 and $2190 \mathrm{~cm}^{-1}$. In this case, it is difficult to determine the oxidation state of vanadium in the respective carbonyls because the ranges of the positions of different $\mathrm{V}^{3+-}$ $\mathrm{CO}$ or $\mathrm{V}^{4+-} \mathrm{CO}$ species overlap. ${ }^{18,20}$ One possibility to elucidate the vanadium oxidation state is to evaluate the stability of these carbonyl complexes. From Figure 6 it can be seen that upon evacuation at $85 \mathrm{~K}$ the bands at 2202 and 2190 $\mathrm{cm}^{-1}$ start to decrease in intensity and finally disappear completely. The low stability of these complexes shows that the bonds between the respective vanadium sites and CO molecules have mainly ó-character. ${ }^{17,18,20}$ These vanadium sites are in a higher oxidation state than $\mathrm{V}^{3^{+}}$ions because our investigations of the stability of $\mathrm{V}^{3+-} \mathrm{CO}$ carbonyls show that these complexes decompose only upon evacuation at $373 \mathrm{~K}$, which is an indication of the synergism between ó- and $\delta$-components in the V3+-C bond. ${ }^{17,18,20-22}$ On the basis of the different stability of the corresponding vanadium carbonyls we can assign the bands at 2202 and $2190 \mathrm{~cm}^{-1}$ to two different types of $\mathrm{V}^{4+-} \mathrm{CO}$ species. ${ }^{17,18,20}$ An additional argument that supports this hypothesis is the lower intensity of these carbonyls in com- 
parison with the intensity of the bands of the $\mathrm{V}^{3+-} \mathrm{CO}$ species. It is well-known ${ }^{18}$ that the formation of $\delta$-backdonation increases the polarization of the adsorbed CO molecules. As a result, the intensity of the bands of the respective carbonyls is higher.

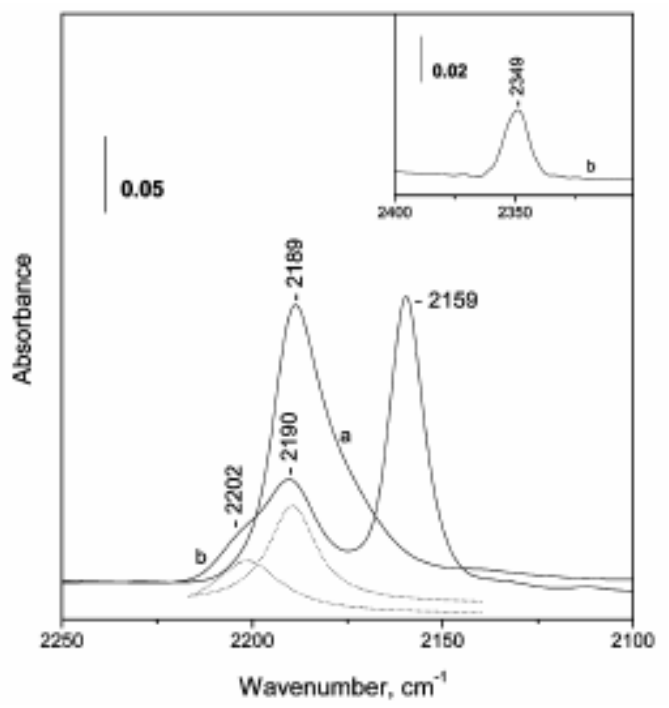

Figure 5: FTIR spectra of CO (0.0004 kPa equilibrium pressure) adsorbed at $298 \mathrm{~K}$ on reduced $\mathrm{V} x \mathrm{O} y / \mathrm{SBA}-15$ (a), addition of $\mathrm{O}_{2}$ (10 kPa equilibrium pressure) at $85 \mathrm{~K}(\mathrm{~b})$, spectrum $\mathrm{b}$ together with the results from a least-square fit (dotted lines).

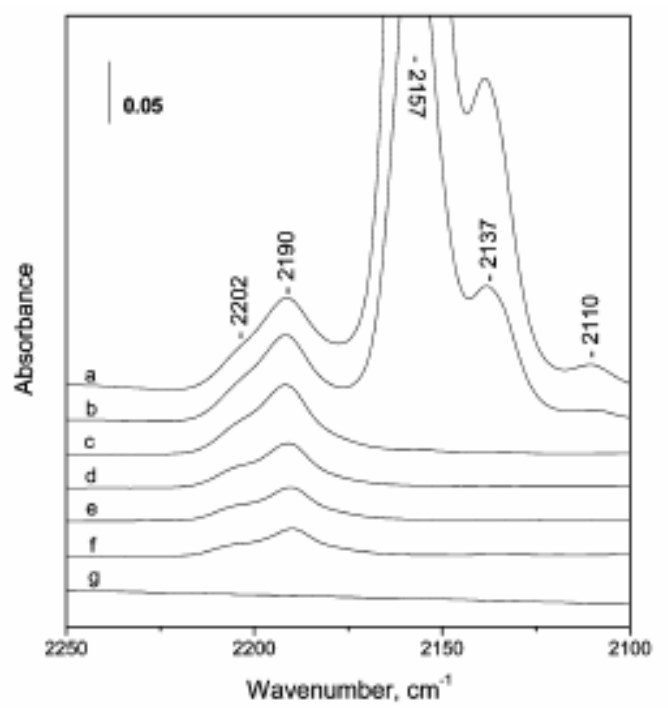

Figure 6: Stability of the carbonyls on the reoxidized $\mathrm{V} x \mathrm{O} y / \mathrm{SBA}-15$ after evacuation at $85 \mathrm{~K}$ with time (a-g). Spectra are offset for clarity.

\subsubsection{Reoxidation of the Sample with $\mathrm{O}_{2}$ at $298 \mathrm{~K}$.}

The initially reduced sample was exposed to $\mathrm{O}_{2}(10$ $\mathrm{kPa}$ equilibrium pressure) at $298 \mathrm{~K}$ and subsequently the sample was cooled to $85 \mathrm{~K}$. CO adsorption on this sample results in the appearance of bands due to $\mathrm{H}$-bonded and physically adsorbed CO only (spectra not shown). The absence of any bands in the spectrum due to vanadium carbonyls demonstrates that all vanadium ions are completely oxidized to $\mathrm{V}^{5+}$.

On the basis of the results obtained after reoxidation of the reduced sample, we can conclude that (i) when the reduced sample is in contact with $\mathrm{O}_{2}$ at low temperature, $\mathrm{V}^{3+}$ sites are partly oxidized to $\mathrm{V}^{4+}$ ions with concomitant formation of $\mathrm{CO}_{2}$ and (ii) contact with $\mathrm{O}_{2}$ at room temperature leads to complete oxidation of $\mathrm{V}^{3+}$ ions to $\mathrm{V}^{5+}$.

\subsection{Adsorption of $N O$ on Reduced $V_{x} O_{y} / S B A$ -} 15.

Similar to CO, NO does not adsorb on the oxidized sample. However, after reduction of the sample with $\mathrm{H}_{2}$ (50 $\mathrm{kPa}$ equilibrium pressure) at $673 \mathrm{~K}$ and subsequent $\mathrm{NO}$ exposure at room temperature, several bands with maxima at 1909, 1830, 1763, 1686, and $1620 \mathrm{~cm}^{-1}$ (Figure 7, spectrum a) were registered in the spectrum. These bands are very stable and still exist even after more than $1 \mathrm{~h}$ of evacuation (Figure 7, spectra b-f). However, upon evacuation at $373 \mathrm{~K}$, the bands at 1909,1830 , and $1763 \mathrm{~cm}^{-1}$ disappear and only the bands at 1686 and $1620 \mathrm{~cm}^{-1}$ are still present (Figure 7, spectrum g). According to the literature ${ }^{17,29-32}$ the bands with maxima at 1909 and $1763 \mathrm{~cm}^{-1}$ are assigned to the symmetric $\left(v_{\mathrm{s}}\right)$ and antisymmetric $\left(v_{\mathrm{as}}\right)$ modes of $\mathrm{V}^{4+}(\mathrm{NO})_{2}$, whereas the bands at 1830 and 1686 $\mathrm{cm}^{-1}$ are characteristic for the symmetric $\left(v_{\mathrm{s}}\right)$ and antisymmetric $\left(V_{\mathrm{as}}\right)$ modes of $\mathrm{V}^{3^{+}}(\mathrm{NO})_{2}$. The formation of these dinitrosyl species shows that the respective $\mathrm{V}^{4+}$ and $\mathrm{V}^{3^{+}}$ ions possess two effective coordination vacancies and as a result can adsorb two NO molecules. ${ }^{17,29-32}$ The detection of $\mathrm{V}^{4^{+}}$and $\mathrm{V}^{3^{+}}$by $\mathrm{NO}$, in contrast to the detection of only $\mathrm{V}^{3^{+}}$ by $\mathrm{CO}$, is explained by partial oxidation of $\mathrm{V}^{3^{+}}$with concomitant formation of nonadsorbing nitrogen compounds.

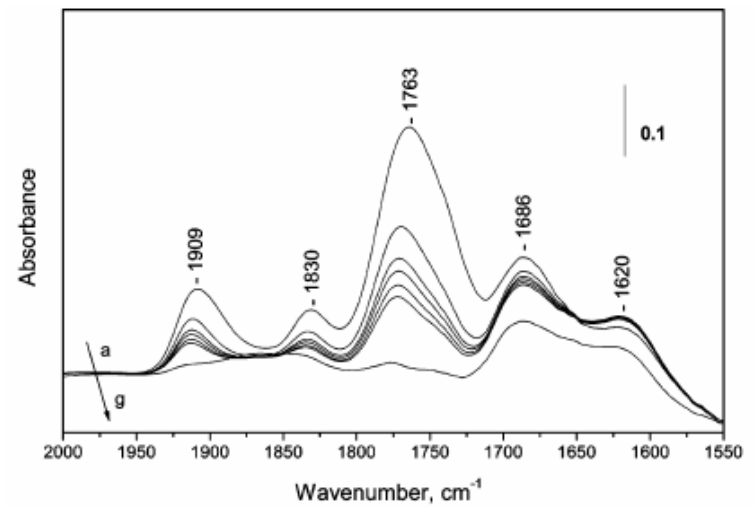

Figure 7: FTIR spectra of NO (0.2 kPa equilibrium pressure) adsorbed at $298 \mathrm{~K}$ on reduced $\mathrm{V} x \mathrm{O} y / \mathrm{SBA}-15$ (a) after evacuation at $298 \mathrm{~K}$ (b-f) and at $373 \mathrm{~K}$ (g). 
The band at $1620 \mathrm{~cm}^{-1}$ could either be due to surface nitro or nitrato complexes, which are obtained as a result of NO oxidation ${ }^{32}$ To obtain more information about the nature of the species responsible for this band, we investigated the reactivity of these complexes toward $\mathrm{O}_{2}$.

\subsection{Coadsorption of $\mathrm{NO}$ and $\mathrm{O}_{2}$ on Reduced $V_{x} O_{y} / S B A-15$.}

$\mathrm{NO}(0.2 \mathrm{kPa}$ equilibrium pressure) adsorption on the reduced sample leads to the appearance of a series of bands with maxima at 1902,1827, 1759, 1740, $1686 \mathrm{~cm}^{-1}$ as well as a weak band at $1620 \mathrm{~cm}^{-1}$ (Figure 8, spectrum a). Analysis of the spectra shows that the band at $1759 \mathrm{~cm}^{-1}$, which was assigned to the îs mode of the $\mathrm{V}^{4+}(\mathrm{NO})_{2}$ species, has a complex character with a shoulder at $1740 \mathrm{~cm}^{-1}$ (Figure 8 , spectrum a). Recently, studying NO adsorption on VSiBEA zeolite, Ivanova et al. ${ }^{29}$ observed a similar behavior, i.e., the splitting of the antisymmetric mode of the $\mathrm{V}^{4+}(\mathrm{NO})_{2}$ complexes into two components. On the basis of these results, the authors suggested the existence of two types of $\mathrm{V}^{4+}(\mathrm{NO})_{2}$ dinitrosyls. These observations fit well with our results obtained after the $\mathrm{CO}$ adsorption, which show that two $\mathrm{V}^{4+}$ sites with different electrophilicity are present in the SBA- 15 matrix. From this point of view we can assign the band at $1740 \mathrm{~cm}^{-1}$ to the îas mode of a second $\mathrm{V}^{4+}(\mathrm{NO})_{2}$ dinitrosyl species. After introduction of $\mathrm{O}_{2}(0.7 \mathrm{kPa}$ equilibrium pressure) into the system all bands decrease in intensity and their maxima are blue-shifted (Figure 8, spectrum b). The fact that after contact with $\mathrm{O}_{2}$ the band at $1620 \mathrm{~cm}^{-1}$ starts to decrease in intensity indicates that this band is not due to nitrates but probably due to anionic oxocompounds containing nitrogen in a lower oxidation state.

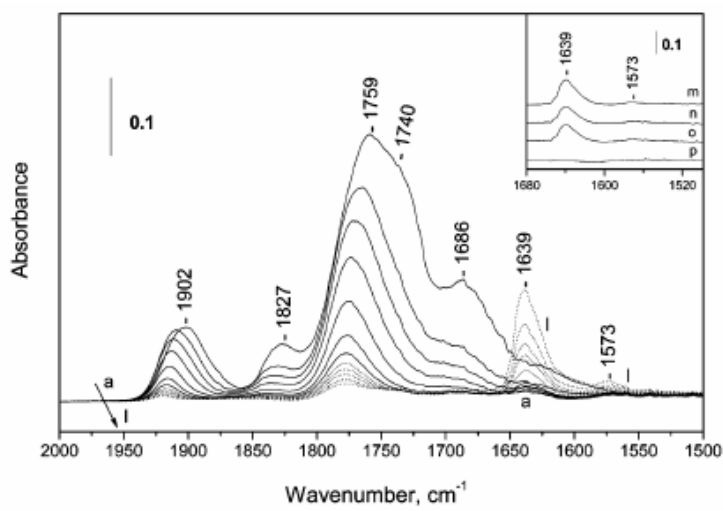

Figure 8: FTIR spectra of NO (0.2 kPa equilibrium pressure) adsorbed at $298 \mathrm{~K}$ on reduced $\mathrm{V} x \mathrm{O} / \mathrm{SBA}-15$ (a), addition of $\mathrm{O}_{2}$ (0.7 $\mathrm{kPa}$ equilibrium pressure) at $298 \mathrm{~K}$ (b), development of the spectra with time (c-j), increasing the amount of $\mathrm{O}_{2}$ to $1 \mathrm{kPa}(\mathrm{k})$ and $2 \mathrm{kPa}(\mathrm{l})$ and (inset) evacuation at $298 \mathrm{~K}(\mathrm{~m})$, at $373 \mathrm{~K}(\mathrm{n})$, at $473 \mathrm{~K}(\mathrm{o})$, and $573 \mathrm{~K}(\mathrm{p})$ (spectra offset for clarity).
We assign this band to the $v_{\text {as }}\left(\mathrm{NO}_{2}\right)$ stretching modes of nitro compounds. ${ }^{32}$ The evolution of the spectra when the sample was kept in the mixture of $\mathrm{NO}$ and $\mathrm{O}_{2}$ shows mainly two things: (i) the bands due to $v_{\mathrm{s}}$ and $v_{\mathrm{as}}$ of $\mathrm{V}^{3+}(\mathrm{NO})_{2}$ decrease in intensity and disappear much faster than the bands of the respective $\mathrm{V}^{4+}(\mathrm{NO})_{2}$ species (Figure 8, spectra b-l) and (ii) simultaneously new bands appear with maxima at 1639 and $1573 \mathrm{~cm}^{-1}$, which are due to surface nitrates (Figure 8, spectra c-l). ${ }^{32}$ The nature and the symmetry of the $\mathrm{NO}_{3}$ - species will be discussed later. As the $\mathrm{NO}$ and $\mathrm{O}_{2}$ mixture is a strongly oxidizing medium, we can explain the decrease in intensity of the $\mathrm{V}^{3+}(\mathrm{NO})_{2}$ - and $\mathrm{V}^{3+}(\mathrm{NO})_{2}$-related bands by reoxidation of the respective $\mathrm{V}^{3^{+}}$and $\mathrm{V}^{4^{+}}$ions to $\mathrm{V}^{5^{+}}$. Thus-formed $\mathrm{V}^{5^{+}}$sites are occupied by surface nitrates, which are characterized by bands at 1639 and $1573 \mathrm{~cm}^{-1} \cdot{ }^{30-32}$ It should be noted that the $\mathrm{V}^{4+}$ ions are more stable under these conditions than the $\mathrm{V}^{3^{+}}$ sites. After increasing the oxygen partial pressure to 1 and $2 \mathrm{kPa}$, respectively, only bands due to the $v_{\mathrm{s}}$ and $v_{\text {as }}$ modes of the $\mathrm{V}^{3+}(\mathrm{NO})_{2}$ species and the surface nitrates are observed (Figure 8, spectra k,l). A comparison of the corresponding band intensities shows that under these conditions the main fraction of the vanadium sites is in a +5 state and only a negligible amount of $\mathrm{V}^{4+}$ ions is present on the surface. The formed nitrates are characterized by very high stability. The bands of these complexes disappeared completely only after evacuation at $573 \mathrm{~K}$ (Figure 8; see inset, spectra m-p).

\subsection{Coadsorption of $\mathrm{CO}$ and NO on Reduced $V_{x} O_{y} / S B A-15$.}

The results of the NO adsorption experiments on the reduced sample showed that $\mathrm{V}^{3+}$ and $\mathrm{V}^{4+}$ possess two effective coordination vacancies and as a result can form dinitrosyl species. Therefore, it was interesting to investigate the possibility of mixed $\mathrm{V}^{3^{+} / 4^{+}}(\mathrm{CO})(\mathrm{NO})$ complex formation after coadsorption of $\mathrm{CO}$ and $\mathrm{NO}$ on the reduced $\mathrm{V} x \mathrm{O} y / \mathrm{SBA}-15$. For this purpose, we investigated both (i) $\mathrm{CO}+\mathrm{NO}$ and (ii) $\mathrm{NO}+\mathrm{CO}$ coadsorption.

\subsubsection{Coadsorption of $\mathrm{CO}$ and NO on Reduced $V_{x} O_{y} / S B A-15$}

CO adsorption (0.5 $\mathrm{kPa}$, equilibrium pressure) on the reduced sample at ambient temperature leads to the appearance of a band at $2187 \mathrm{~cm}^{-1}$ with a low frequency shoulder, both assigned to $\mathrm{V}^{3+-} \mathrm{CO}$ carbonyls (Figure 9, spectrum a). However, after introduction of $\mathrm{NO}(0.5 \mathrm{kPa}$, equilibrium pressure) into the system the following changes in the spectra are observed: (i) in the $2250-2000 \mathrm{~cm}^{-1}$ region the band due to $\mathrm{V}^{3+-} \mathrm{CO}$ carbonyls disappears, whereas another lowintensity band with a maximum at $2108 \mathrm{~cm}^{-1}$ appears in the spectrum (Figure 9, spectrum b, superimposed gas-phase CO visible due to low intensity). With time the intensity at $2108 \mathrm{~cm}-1$ decreases until the band is barely distinguish 

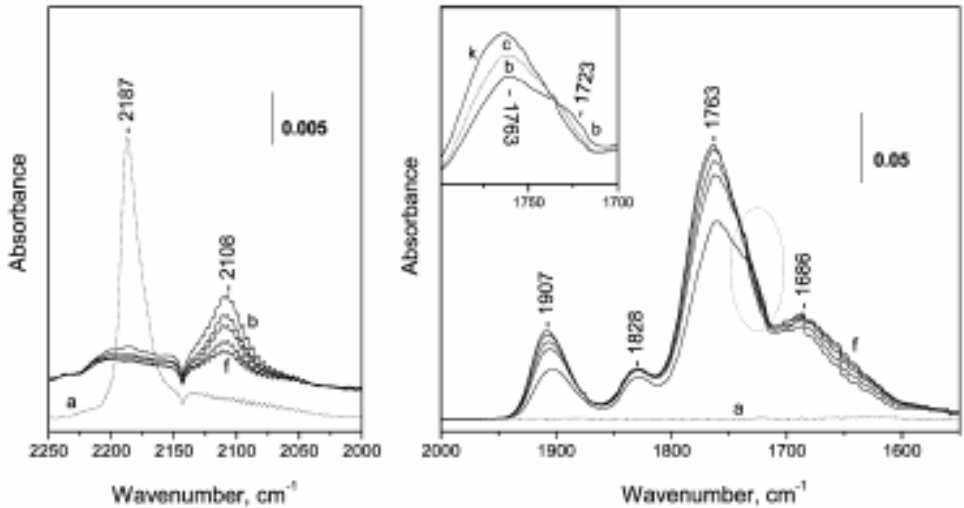

Figure 9: FTIR spectra of CO (0.56 kPa equilibrium pressure) adsorbed at $298 \mathrm{~K}$ on reduced $\mathrm{V} x \mathrm{O} y / \mathrm{SBA}-15$ (a), addition of NO ( $0.5 \mathrm{kPa}$ equilibrium pressure) at $298 \mathrm{~K}$ (b), and development of the spectra with time (c-f). Spectrum a in the left panel is offset for clarity.
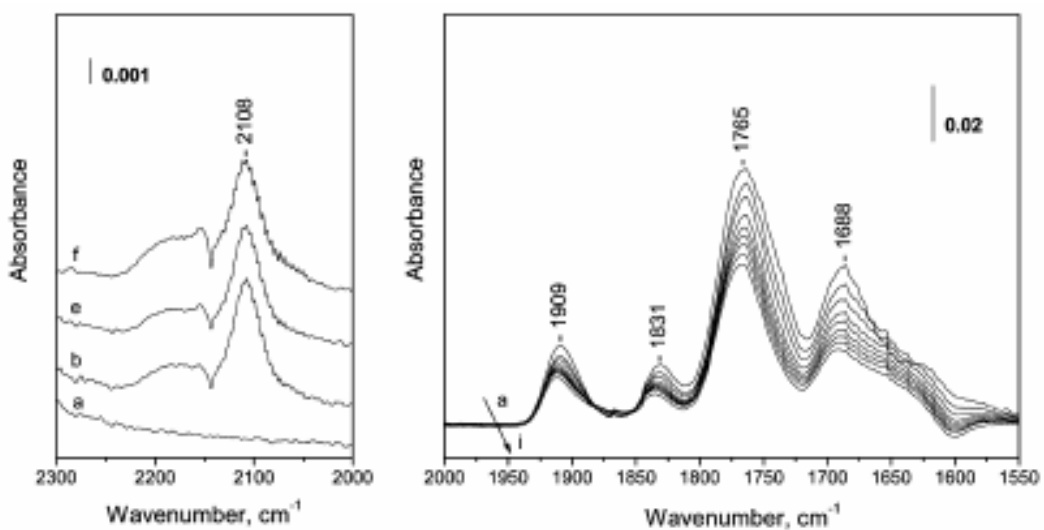

Figure 10: FTIR spectra of NO (0.5 kPa equilibrium pressure) adsorbed at $298 \mathrm{~K}$ on reduced VxOy/SBA-15 (a), addition of CO ( $0.5 \mathrm{kPa}$ equilibrium pressure) at $298 \mathrm{~K}$ (b), and development of the spectra with time (c-i). Spectra shown in the left panel are offset for clarity.

able (Figure 9, spectra c-f). The appearance of a $v(\mathrm{CO})$ stretching band at such a low frequency is quite unusual for cationic vanadium and, to the best of our knowledge, has not been reported previously in the literature. As mentioned before, the lowest-frequency bands of cationic vanadium carbonyls are those of $\mathrm{V}^{2+-} \mathrm{CO}$ complexes, which absorb typically around $2150 \mathrm{~cm}^{-1}$. During their investigation of the adsorption properties of vanadium atoms deposited on an ultrathin silica film, Immaraporn et al. ${ }^{49}$ detected a band at $2075 \mathrm{~cm}^{-1}$ at $\mathrm{CO}$ saturation coverage, which was assigned to $\mathrm{V}(\mathrm{CO})_{3}$ tricarbonyls. We can expect that the oxidation state of vanadium in our case is either +3 or +4 because of (i) the existence of the band at $2187 \mathrm{~cm}^{-1}$ due to $\mathrm{V}^{3+-} \mathrm{CO}$ species after initial adsorption of $\mathrm{CO}$ and (ii) subsequent introduction of NO into the system, which is an oxidizing medium. On the basis of these considerations, we can exclude the possibility that this band is due to carbonyls formed with participation of vanadium atoms. Another possible explanation for the presence of the band at 2108 $\mathrm{cm}^{-1}$ may be that it is not due to "pure" vanadium carbonyls. Taking into account that this band was registered only after coadsorption of $\mathrm{CO}$ and NO, we can propose that it could be due to the $v(\mathrm{CO})$ stretching mode of $\mathrm{V}^{3^{+} / 4^{+}}(\mathrm{CO})(\mathrm{NO})$ mixed complexes, as discussed later.
Simultaneously with the appearance of the band at $2108 \mathrm{~cm}^{-1}$, bands due to $\mathrm{V}^{4+}(\mathrm{NO})_{2}$ and $\mathrm{V}^{3+}(\mathrm{NO})_{2}$ dinitrosyls start to develop in the $2000-1600 \mathrm{~cm}-1$ region of the spectrum (Figure 9, spectrum b). Analysis of the shape of the band of the vas mode of the $\mathrm{V}^{4+}(\mathrm{NO})_{2}$ complexes at $1763 \mathrm{~cm}-1$ shows that initially there is a small shoulder at $1723 \mathrm{~cm}-1$ (Figure 9; see inset, spectrum b). With time all bands in the 2000-1600 $\mathrm{cm}^{-1}$ region increase in intensity while the intensity of the $1723 \mathrm{~cm}^{-1}$ band decreases. The temporal behavior of this band is quite similar to that of the band at $2108 \mathrm{~cm}^{-1}$; therefore, we can propose that the band at $1723 \mathrm{~cm}^{-1}$ is probably due to the $v(\mathrm{NO})$ stretching mode of the respective mixed complexes. However, it should be noted that this assignment is questionable, because of the presence of very intense bands of the $\mathrm{V}^{4+}(\mathrm{NO})_{2}$ and $\mathrm{V}^{3+}(\mathrm{NO})_{2}$ dinitrosyls in that region, which are overlapping with the respective band and hindering the interpretation of the spectra. The comparison of the behavior of the bands at 1763 and $1723 \mathrm{~cm}^{-1}$ shows that an isosbestic point is located between them, which is an indication for the interconversion of the respective species (Figure 9; see inset, spectra b,c,k). 


\subsubsection{Coadsorption of NO and CO on Reduced $V_{x} O_{y} / S B A-15$.}

To investigate the nature of the species that are responsible for the band at $2108 \mathrm{~cm}-1$, additional coadsorption experiments of $\mathrm{NO}(0.5 \mathrm{kPa}$, equilibrium pressure $)$ and $\mathrm{CO}(0.5 \mathrm{kPa}$, equilibrium pressure) were performed. It can be seen from Figure 10 that after the initial adsorption of NO (0.5 $\mathrm{kPa}$, equilibrium pressure) only bands due to $\mathrm{V}^{4+}(\mathrm{NO})_{2}$ and $\mathrm{V}^{3+}(\mathrm{NO})_{2}$ dinitrosyls (Figure 10 , spectrum a) appear. No adsorbate-related bands are detected in the 2300-2000 $\mathrm{cm}^{-1}$ region. However, after CO adsorption (0.5 $\mathrm{kPa}$, equilibrium pressure) the band at $2108 \mathrm{~cm}^{-1}$ appears in the spectrum. The fact that this band has not been observed after adsorption of CO (Figure 9, spectrum a) or NO (Figure 10 , spectrum a) but after coadsorption of $\mathrm{CO}+\mathrm{NO}$ or $\mathrm{NO}+\mathrm{CO}$ strongly supports the idea about the formation of mixed carbonylnitrosyls. While the intensity of the band at $2108 \mathrm{~cm}^{-1}$ does not change significantly with time, the bands of the dinitrosyl species at $2000-1550 \mathrm{~cm}^{-1}$ decrease in intensity (Figure 10, spectra b-f).

\section{Discussion}

\subsection{Redox Properties of Vanadium lons in $\mathrm{V}_{x} \mathrm{O}_{y} / \mathrm{SBA}-15$}

In the initial state after activation in vacuum, no $\mathrm{CO}$ or NO complexes were formed at $85 \mathrm{~K}$ or room temperature, respectively. This observation suggests that vanadium is in a coordinatively saturated +5 state and supports the opinion that $\mathrm{V}^{5^{+}}$ions do not form carbonyl or nitrosyl complexes. ${ }^{17,18,20-28}$ Unfortunately, we cannot obtain further information about the state of the $\mathrm{V}^{5+}$ ions because the fundamental vibrations of vanadyl (VdO) groups overlap with support absorptions and the overtones are apparently too weak.

The state of the SBA-15-supported vanadia could be altered through reduction and oxidation treatments, and the positions and assignments of the bands observed after CO and NO adsorption are summarized in Table 1. Criteria for the distinction of carbonyl complexes are (i) stability and (ii) band intensity. The $\mathrm{V}^{4+-} \mathrm{CO}$ complexes are decomposed after evacuation at $85 \mathrm{~K}$. The low stability of these complexes indicates that the $\mathrm{V}^{4+}$ sites coordinate to $\mathrm{CO}$ mainly via a ó-bond, ${ }^{17,18,20}$ which also results in a low intensity of the respective carbonyl bands. The $\mathrm{V}^{3+-} \mathrm{CO}$ complexes are stable up to $373 \mathrm{~K}$ (Figure 3). The high stability of these species indicates synergism between ó- and $ð$-components of the bond between vanadium ions and adsorbed CO molecules. ${ }^{17,18,20}$ Formation of the $\delta$-component strongly increases the polarization of the CO dipole, and as a result, the respective carbonyls are characterized by more intense bands. $^{18}$

The $\mathrm{V}^{5+}$ sites are not reduced through treating the sample in $\mathrm{H}_{2}$ at $573 \mathrm{~K}$, indicating that these sites are very stable. After heating the sample to $673 \mathrm{~K}_{\text {in }} \mathrm{H}_{2}, \mathrm{~V}^{5^{+}}$sites are reduced to $\mathrm{V}^{3+}$ ions, probably via elimination of water. This result is consistent with the results of the XPS experiments, which show that after treatment in $\mathrm{H}_{2}$ at $688 \mathrm{~K}$ for 1 h, $50 \%$ of $\mathrm{V}^{5^{+}}$is reduced to $\mathrm{V}^{3+}$. Two carbonyl bands at 2189 and $2177 \mathrm{~cm}^{-1}$ indicate two types of $\mathrm{V}^{3+}$ species. In the presence of oxygen at $85 \mathrm{~K}$, these $\mathrm{V}^{3^{+}}$sites are reoxidized to $\mathrm{V}^{4+}$ ions. Upon exposure to oxygen at room temperature, the $\mathrm{V}^{3+}$ sites are fully oxidized toV $\mathrm{V}^{5+}$ ions, because carbonyl complexes cannot be formed anymore. The milder oxidizing agent $\mathrm{NO}$ leads to partial oxidation of $\mathrm{V}^{3+}$ to $\mathrm{V}^{4+}$ at room temperature.

The data demonstrate that the release of oxygen from the SBA-15-supported vanadia species, at least with $\mathrm{H}_{2}$ as the reducing agent, is difficult and requires a temperature as high as $673 \mathrm{~K}$. On the other hand, uptake of oxygen and reoxidation of $\mathrm{V}^{3+}$ to $\mathrm{V}^{4^{+}}$or $\mathrm{V}^{5^{+}}$is facile and rapid. Coordination vacancies of the reduced species are easily replenished by oxygen transfer from molecular $\mathrm{O}_{2}$ or NO. A similar type of redox behavior as described above for $\mathrm{V} x \mathrm{O} y / \mathrm{SBA}-15$ has also been observed for other silicasupported vanadia catalysts, ${ }^{17,18,20}$ demonstrating its more general character.

For applications in partial oxidation catalysis, it is expected that the transfer of oxygen to the substrate is ratelimiting and not the catalyst reoxidation. Indeed, Argyle et al. ${ }^{50}$ found that the rate constant for reoxidation of $\mathrm{V} x \mathrm{O} y / \mathrm{Al}_{2} \mathrm{O}_{3}$ catalyst during propane oxidative dehydrogenation is 3-5 times larger than that for the $\mathrm{C}-\mathrm{H}$ bond activation reduction step. In the light of our data, the release of oxygen, which is tightly bound to the vanadium, will pose a significant activation barrier. Hence, the reason for the slow first step must not be the difficult activation of the substrate. This point can be further elucidated using different reducing agents.

\subsection{Coordination State of Vanadium lons in $V_{x} O_{y} / S B A-15$.}

Similarly to other authors ${ }^{29}$ our results show that NO is a better molecule than $\mathrm{CO}$ to determine the coordination state of the vanadium ions. NO adsorption on reduced $\mathrm{V} x \mathrm{Oy} / \mathrm{SBA}-15$ (Figure 7) reveals that $\mathrm{heV}^{3^{+}}$and $\mathrm{V}^{4^{+}}$ions possess two effective coordinative vacancies and as a result can form dinitrosyl species. The formation of $\mathrm{V}^{3+}(\mathrm{NO})_{2}$ and $\mathrm{V}^{4+}(\mathrm{NO})_{2}$ complexes after NO adsorption has been observed before on other vanadiumcontaining samples, such as $\mathrm{V} / \mathrm{SiO}_{2}{ }^{17}$, $\mathrm{VSiBEA}^{29}{ }^{29} \mathrm{~V} / \mathrm{TiO}_{2},{ }^{17,30} \mathrm{~V}_{2} \mathrm{O}_{5} / \mathrm{ZrO}_{2}{ }^{31}$ and $\mathrm{V}_{2} \mathrm{O}_{5} / \mathrm{Al}_{2} \mathrm{O}_{3}{ }^{17}$ Comparison of these results indicates that the formation of dinitrosyl species is a property that depends mainly on the state of the vanadium ions while the role of the support is minor. We believe that it is due to these properties that the $\mathrm{V}^{3+}$ or $\mathrm{V}^{4+}$ ions in the matrix of SBA-15 are able to coordinate simultaneously CO and NO to form the respective $\mathrm{V}^{3+/ 4^{+}}(\mathrm{CO})(\mathrm{NO})$ mixed complexes, which are characterized by bands at 2108 and $1723 \mathrm{~cm}^{-1}$. Analysis of the literature data ${ }^{51,52}$ shows that previously only results for bulk mixed carbonyl-nitrosyls of vanadium 
were presented. There is no report on mixed carbonylnitrosyl surface species. In 1961, Hieber et al. ${ }^{52}$ reported the preparation of a $\mathrm{V}(\mathrm{CO})_{5} \mathrm{NOcomplex}$, which is characterized by very low thermal stability. Later this compound was isolated and characterized by infrared spectroscopy. The following bands were reported: $v(\mathrm{NO}), 1695 \mathrm{~cm}^{-1}$; $v(C O), 2100,2050,1990 \mathrm{~cm}^{-1} .{ }^{51}$ These results show that vanadium is able to simultaneously coordinate $\mathrm{CO}$ and $\mathrm{NO}$ molecules.

\subsection{Heterogeneity of Vanadium lons in $V_{x} O_{y} / S B A-15$.}

As shown above, after reduction of $\mathrm{V} x \mathrm{O} y / \mathrm{SBA}-15$ with $\mathrm{H}_{2}$ at $673 \mathrm{~K}$, two bands were observed in the IR spectra, which are due to $\mathrm{V}^{3+-} \mathrm{CO}$ carbonyls. The presence of two bands suggests that in the channels of the support two different kinds of $\mathrm{V}^{3+}$ ions are present. A similar effect has also been observed by other authors for $\mathrm{CO}$ adsorption on $\mathrm{V} / \mathrm{SiO}_{2} \cdot{ }^{17,21}$ Comparison of the results of these authors and our data shows that the heterogeneity of the vanadium species is influenced by the chemical composition but not the structure of the support. On the basis of FTIR and UVvis spectroscopic data, Davydov ${ }^{17}$ and Jonson et al. ${ }^{21}$ have proposed that the two vanadium sites are characterized by different coordination numbers. There are several possible causes for this effect. One of them is that in the channels of SBA-15 there are (i) isolated and (ii) associated vanadium sites. In this light, Jonson et al. ${ }^{21}$ have reported that with increasing vanadium content the position of the main band of the $\mathrm{V}^{3+-}$ COspecies is blue-shifted. After $\mathrm{CO}$ adsorption on reduced $0.1 \mathrm{wt} \% \mathrm{~V} / \mathrm{SiO}_{2}\left(315 \mathrm{~m}^{2} / \mathrm{g}\right)$ they found a band at $2183 \mathrm{~cm}^{-1}$, while for $2 \mathrm{wt} \% \mathrm{~V} / \mathrm{SiO}_{2}\left(265 \mathrm{~m}^{2} / \mathrm{g}\right)$ the band of the respective complexes appeared at $2187 \mathrm{~cm}^{-1}{ }^{21}$ This indicates that the position of the $\mathrm{V}^{3+-} \mathrm{CO}$ related band is very sensitive to the vanadium content. In our case (2.7 wt $\% \mathrm{~V})$, the band maximum was located at $2189 \mathrm{~cm}^{-1}$, which suggests that the vanadium sites in the matrix of SBA-15 are partly associated.

Another possible reason for the heterogeneity of the vanadium sites is that one of these sites is bound to isolated hydroxyl groups. This model has been proposed in the literature for $\mathrm{V} / \mathrm{TiO}_{2}{ }^{6,22,50}$ and $\mathrm{V} / \mathrm{Al}_{2} \mathrm{O}_{3}-\mathrm{TiO}_{2}{ }^{22}$. In this case, the respective vanadium sites are characterized by different surroundings, which could explain the difference in their electrophilicity. However, before and after reduction of the sample we did not observe any additional bands due to O-H vibrations of hydroxylgroups, which could be assigned to $\mathrm{OH}$ coordinated to vanadium sites. Therefore, we believe that this hypothesis can be ruled out in our case.

Previous results ${ }^{33}$ have shown that during the synthesis of $\mathrm{V} x \mathrm{O} y / \mathrm{SBA}-15$ the vanadia precursor interacts with the surface silanol groups of the support. We have observed two different kinds of surface silanol groups, which might play a role as adsorption sites for vanadium. Previously, several authors ${ }^{45,54,55}$ have proposed the presence of different kinds of silanol groups on $\mathrm{SiO}_{2}$. Hair and Hertl ${ }^{55}$ have proposed that the band due to the $v(\mathrm{O}-\mathrm{H})$ vibrations of silanol groups consists of three components. An explanation has been given by other authors, ${ }^{45,54}$ who suggested that silanol groups could be distinguished into (i) isolated, (ii) geminal, and (iii) vicinal hydroxyl groups. Hence, one would expect the carbonyl complexes of vanadium ions located on isolated and geminal silanol groups to have slightly different frequencies. ${ }^{56}$

\subsection{Symmetry of Surface Nitrates.}

The free $\mathrm{NO}_{3}{ }^{-}$ion has $D_{3 h}$ symmetry. Therefore, it has only one infrared active mode $v_{3}$ at $1380 \mathrm{~cm}^{-1}$. The respective $v_{1}$ mode is Raman-active. ${ }^{32}$ However, nitrates coordinated to the surface have lower symmetry $\left(C_{2} \mathrm{~V}\right)$. As a result, the respective $v_{3}$ mode splits into two components $v_{s}$ $\left(\mathrm{NO}_{2}\right)$ and $v_{\text {as }}\left(\mathrm{NO}_{2}\right)$ and the $v_{3}$ mode becomes IR-active. The value of the splitting between $v_{\mathrm{s}}\left(\mathrm{NO}_{2}\right)$ and $v_{\mathrm{as}}-\left(\mathrm{NO}_{2}\right)$ and the position of the $v_{1}$ mode depend on the (i) symmetry and the (ii) strength of the bond between the nitrates and the surface sites. The splitting between the $v_{s}\left(\mathrm{NO}_{2}\right)$ and $V_{\text {as }}\left(\mathrm{NO}_{2}\right)$ modes of nitrates decreases in the following order: bridged $>$ bidentate $>$ monodentate nitrates. ${ }^{32}$ From this point of view, the differences in the position of the $v_{s}$ $\left(\mathrm{NO}_{2}\right)$ and $v_{\mathrm{as}}-\left(\mathrm{NO}_{2}\right)$ related bands of the nitrates could be useful for the determination of the symmetry of the respective nitrates. Unfortunately, in our case the bands due to the $v_{s}\left(\mathrm{NO}_{2}\right)$ and $v_{1}$ stretching modes of the nitrates are masked by the intrinsic absorbance of $\mathrm{V} x \mathrm{O} y / \mathrm{SBA}-15$,hindering the determination of the symmetry of the $\mathrm{NO}_{3}$-complexes. However, the symmetry of the nitrates can also be identified solely on the basis of the position of the $v_{\mathrm{as}}-\left(\mathrm{NO}_{2}\right)$ stretching mode. Miyata et al. ${ }^{31}$ observed a series of bands at $1629,1180 \mathrm{~cm}^{-1}$ and at $1581,1220 \mathrm{~cm}^{-1}$ after adsorption of $\mathrm{NO}_{2}$ on $\mathrm{V}_{2} \mathrm{O}_{5} / \mathrm{ZrO}_{2}$, which were assigned to bridged and bidentate nitrates, respectively. For the adsorption of $\mathrm{NO}_{2}$ onto $\mathrm{V} / \mathrm{TiO}_{2}$, Dines et al. ${ }^{30}$ observed the formation of nitrate bands at 1643,1572 , and $1535 \mathrm{~cm}^{-1}$, which they assigned to bridged, bidentate, and monodentate species, respectively. These authors ${ }^{30}$ believe that the respective nitrato species form after interaction of $\mathrm{NO}_{2}$ with oxygen from the vanadyl groups. By analogy to these results, we can assign the bands at 1639 and $1573 \mathrm{~cm}^{-1}$ in our spectra to the $V_{\mathrm{as}}-\left(\mathrm{NO}_{2}\right)$ stretching modes of bridged and bidentate $\mathrm{NO}_{3}$-complexes. Importantly, the formation of bridged nitrates points to the presence of associated vanadium surface species (dimmers or polymers) on $2.7 \mathrm{wt} \%$ V/SBA15 , i.e., well below the $\mathrm{V}$ loading at which $\mathrm{V}_{2} \mathrm{O}_{5}$ crystal formation has been observed by Raman spectroscopy $(\approx 9 \mathrm{wt} \% \mathrm{~V}) .^{33}$ These findings are supported by the results of the $\mathrm{CO}$ adsorption experiments, as discussed above. 


\section{Summary}

After treatment of $\mathrm{V} x \mathrm{O} y / \mathrm{SBA}-15$ in $\mathrm{H}_{2}$ at $673 \mathrm{~K}, \mathrm{~V}^{5+}$ sites are reduced toV3+ ions. Thus-obtainedV3+ ions are easily reoxidized, namely to $\mathrm{V}^{4+}$ in the presence of $\mathrm{O}_{2}$ at low temperature $(85 \mathrm{~K})$, to a mixture of $\mathrm{V}^{3+} / \mathrm{V}^{4+}$ in the presence of $\mathrm{NO}$ at room temperature, and completely to $\mathrm{V}^{5+}$ through $\mathrm{O}_{2}$ at room temperature. Hence, reoxidation is much more facile than reduction.

Two types of $\mathrm{V}^{3+}$ or $\mathrm{V}^{4+}$ are detected, indicating vanadium sites of different electrophilicity in the matrix of silica SBA-15. A fraction of the V sites is most likely associated at a content of $2.7 \mathrm{wt} \% \mathrm{~V}$.

The $\mathrm{V}^{3+}$ and $\mathrm{V}^{4+}$ ions possess two effective coordinative vacancies. As a result, they can adsorb (i) two NO molecules to form the respective $\mathrm{V}^{3+}(\mathrm{NO})_{2}$ and $\mathrm{V}^{4+}(\mathrm{NO})_{2}$ dinitrosyls and (ii) one $\mathrm{CO}$ and one NO molecule to form mixed carbonyl-nitrosyls.

\section{References}

[1] Kung, H. H. AdV. Catal. 1994, 1, 40.

[2] Banares, M.; Gao, X.; Fierro, J. L. G.; Wachs, I. E. Stud. Surf. Sci. Catal. 1997, 110, 295.

[3] Argyle, M. D.; Chen, K.; Bell, A. T.; Iglesia, E. J. Catal. 2002, 208, 139.

[4] Buyevskaya, O. V.; Bru"ckner, A.; Kondratenko, E. V.; Wolf, D.; Baerns, M. Catal. Today 2001, 67, 369.

[5] Dias, C. R.; Portela, M. F.; Bond, G. C. J. Catal. 1995, 157, 344.

[6] Bond, G. C.; Tahir, S. F. Appl. Catal. 1991, 71, 1.

[7] Deo, G.; Wachs, I. E.; Haber, J. Crit. ReV. Surf. Chem. 1994, 4, 141.

[8] Vogt, E. T. V.; Boot, A.; Dillen, A. J.; Geus, J. W.; Janssen, F. J. J. G.; Kerkhof, F. M. G. J. Catal. 1988, 114, 313.

[9] Khodakov, A.; Olthof, B.; Bell, A. T.; Iglesia, E. J. Catal. 1999, 181, 205.

[10] Khodakov, A.; Yang, J.; Su, S.; Iglesia, E.; Bell, A. T. J. Catal. 1998, 177, 343.

[11] Puglisi, M.; Arena, F.; Frusteri, F.; Sokolovskii, V.; Parmaliana, A. Catal.Lett. 1996, 41, 41.

[12] Takahara, I.; Saito, M.; Inaba, M.; Murata, K. Catal. Lett. 2005, 102, 201.

[13] Deo, G.; Wachs, I. E. J. Catal. 1994, 146, 323.

[14] Roosebom, F.; Pillen, A. J.; Geus, J. W.; Gellings, P. J. Ind. Eng. Chem. Prod. Res. DeV. 1981, 20, 304.

[15] Mori, K.; Miyamoto, A.; Murakami, Y. J. Chem. Soc., Faraday Trans. 1986, 82, 13.

[16] Weckhuysen, B. M.; Keller, D. E. Catal. Today, 2003, 78, 25.

[17] Davydov, A. A. Kinet. Katal. 1993, 34, 1056.

[18] Hadjiivanov, K.; Vayssilov, G. Adv. Catal. 2002, 47, 305.

[19] Davydov, A. IR Spectroscopy Applied to Surface Chemistry of Oxides; Nauka: Novosibirsk, 1984.

[20] Jonson, B.; Rebenstorf, B.; Larrson, R.; Andersson, S. L. T. J. Chem. Soc. Faraday Trans. 1988, 84, 1897.

[21] Concepción, P.; Reddy, B. M.; Knözinger, H. Phys. Chem. Chem. Phys. 1999, 1, 3031.

[22] Davydov, A.; Budneva, A.; Maksimov, N. G. React. Kinet. Catal. Lett. 1982, 20, 93.

[23] Sobalic, Z.; Kozlovski, R.; Haber, J. J. Catal. 1991, 127, 665.

[24] Gerasimov, S.; Filimonov, V. Kinet. Katal. 1981, 22, 469.

\section{Acknowledgement}

The authors are grateful to Jutta Kröhnert for helpful discussions. Robert Schlögl is kindly acknowledged for continuous support of the project. This work is supported by SFB 546 of the Deutsche Forschungsgemeinschaft (DFG). Tz.V. would like to thank the Max-Planck Society for a stipend. C.H. thanks the Deutsche Forschungsgemeinschaft (DFG) for providing an Emmy Noether fellowship.

[25] Jonson, B.; Rebenstorf, B.; Larrson, R. Acta Chem. Scand. A, 1988, 42, 156.

[26] Jonson, B.; Rebenstorf, B.; Larrson, R.; Andersson, S. L. T. J. Chem. Soc. Faraday Trans. 1988, 84, 3363.

[27] Busca, G.; Ramis, G.; Lorenzelli, V. J. Mol. Catal. 1989, 50, 231.

[28] Ivanova, E.; Hadjiivanov, K.; Dzwigaj, S.; Che, M. Microporous Mesoporous Mater. 2006, 89, 69.

[29] Dines, T.; Rochester, C.; Ward, A. J. Chem. Soc. Faraday Trans. 1991,87, 1617.

[30] Miyata, H.; Konishi, S.; Ohno, T.; Hatayama, F. J. Chem. Soc. Faraday Trans. 1995, 91, 1557.

[31] Hadjiivanov, K. Catal. ReV.-Sci. Eng. 2000, 42, 71.

[32] a) Hess, C.; Hoefelmeyer, J. D.; Tilley, T. D. J. Phys. Chem. B, 2004,108, 9703. b) Hess, C.; Wild, U.; Schlögl, R. Microporous Mesoporous Mater. 2006, 95, 339.

[33] Hess, C. Surf. Sci. 2006, 600, 3695.

[34] Zhao, D. Y.; Feng, J. L.; Huo, Q. S.; Melosh, N.; Fredrickson, G. H.; Chmelka, B. F.; Stucky, G. D. Science 1998, 279, 548.

[35] Hess, C.; Drake, I. J.; Hoefelmeyer, J. D.; Tilley, T. D.; Bell, A. T. Catal. Lett. 2005, 105, 1.

[36] Hess, C.; Looi, M. H.; Abd Hamid, S. B.; Schlögl, R. Chem. Commun. 2006, 451.

[37] Lopez, H. H.; Martinez, A. Catal. Lett. 2002, 83, 37.

[38] Liu, Y.-M.; Cao, Y.; Li, N.; Feng, W.-L.; Dai, W.-L.; Yan, S.-R.; He, H.-Y.; Fan, K.-N. J. Catal. 2005, 224, 417.

[39] Segura, Y.; Cool, P.; Kustrowski, P.; Chmielarz, L.; Dziembaj, R.; Vansant, E. F. J. Phys. Chem. B 2005, 109, 12071.

[40] Ruddy, D. A.; Ohler, N. L.; Bell, A. T.; Tilley, T. D. J. Catal. 2006, 238, 277.

[41] Carvalho, W. A.; Wallau, M.; Schuchardt, U. J. Mol. Catal. A 1999, 144, 91.

[42] Roman, P.; Aranzabe, A.; Luque, A.; Gutierrez-Zorilla, J. M. Mat. Res. Bull. 1991, 26, 731.

[43] (a) Klaasen, M.; Berndtsson, A.; Hedman, J.; Nilsson, R.; Nyholm, R.; Nordling, C. J. Electron. Spectrosc. Relat. Phenom. 1974, 3, 427. (b) Morgan, W. E.; Van Wazer, J. R. J. Phys. Chem. 1973, 77, 96. (c) Barr, T. L. Appl. Surf. Sci. 1983, 15, 1.

[44] Boehm, H.; Knözinger, H. Nature and Estimation of Functional Groups on Solid Surfaces. In CatalysissScience and 
Technology; Anderson, J. R., Boudart, M., Eds.; SpringerVerlag: New York, 1983, Vol. 4, pp 39-207.

[45] Zarubin, D. P. J. Non-Cryst. Solids 2001, 286, 80.

[46] Horvath, B.; Struntz, J.; Geyer, J.; Horvath, E. G. Z. Anorg. Allg. Chem. 1981, 483, 181.

[47] Dutoit, D. C. M.; Schneider, M.; Fabrizioli, P.; Baiker, A. J. Mater. Chem. 1997, 7, 271.

[48] Immaraporn, B.; Magg, N.; Kaya, S.; Wang, J.; Bäumer, M.; Freund, H.-J. Chem. Phys. Lett. 2004, 392, 127.

[49] Argyle, M. D.; Chen, K.; Iglesia, E; Bell, A. T. J. Phys. Chem. B 2005, 109, 2414.

[50] Fjare, K.; Ellis, J. J. Am. Chem. Soc. 1983, 105, 2303.
[51] Hieber, W.; Peterhans, J.; Winter, E. Chem. Ber. 1961, 94, 2572.

[52] Kantcheva, M. M.; Hadjiivanov, K. I.; Klissurski, D. G. J. Catal. 1992, 134, 299.

[53] Boehm, H. P. Adv. Catal. 1966, 16, 179.

[54] Hair, M. L.; Hertl, W. J. Phys. Chem. 1969, 73, 2372.

[55] Shenderovich, I. G.; Buntkowsky, G.; Schreiber, A.; Gedat, E.; Sharif, S.; Albrecht, J.; Golubev, N. S.; Findenegg, G. H.; Limbach, H. H. J. Phys. Chem. B 2003, 107, 11924.

[56] Weidlein, J.;Müller, U.; Dehnicke, K. Schwingungsspektroskopie; Georg Thieme Verlag Stuttgart: New York, 1988. 